\title{
Modeling of inelastic transport in one-dimensional metallic atomic wires
}

\author{
Frederiksen, Thomas; Brandbyge, Mads; Lorente, N; Jauho, Antti-Pekka
}

Published in:

10th International Workshop on Computational Electronics, 2004. IWCE-10 2004. Abstracts.

Link to article, DOI:

10.1109/IWCE.2004.1407408

Publication date:

2004

Document Version

Publisher's PDF, also known as Version of record

Link back to DTU Orbit

Citation (APA):

Frederiksen, T., Brandbyge, M., Lorente, N., \& Jauho, A-P. (2004). Modeling of inelastic transport in onedimensional metallic atomic wires. In 10th International Workshop on Computational Electronics, 2004. IWCE-10 2004. Abstracts. IEEE. https://doi.org/10.1109/IWCE.2004.1407408

\section{General rights}

Copyright and moral rights for the publications made accessible in the public portal are retained by the authors and/or other copyright owners and it is a condition of accessing publications that users recognise and abide by the legal requirements associated with these rights.

- Users may download and print one copy of any publication from the public portal for the purpose of private study or research.

- You may not further distribute the material or use it for any profit-making activity or commercial gain

- You may freely distribute the URL identifying the publication in the public portal 


\section{MODELING OF INELASTIC TRANSPORT IN ONE-DIMENSIONAL METALLIC ATOMIC WIRES}

Thomas Frederiksen, Mads Brandbyge, Nicolas Lorente, ${ }^{1}$ and Antti-Pekka Jauho

1) MIC - Department of Micro and Nanotechnology, Technical University of Denmark, Ørsteds Plads, Bldg. 345E, DK-2800 Lyngby, Denmark

2) Laboratorie Collisions, Agrégats, Réactivité, IRSAMC, Université Paul Sabatier, 118 Route de Narbonne, F-31062 Toulouse, France, cédex

E-mail: thf@mic.dtu.dk

Atomic-size conductors represent the ultimate limit of miniaturization, and understanding their properties is an important problem in the fields of nanoelectronics and molecular electronics. Quantum effects become important which leads to a physical behavior fundamentally different from macroscopic devices. During the last decade various experimental techniques have been developed to create and probe properties of such small objects [1]. For instance, it is possible with some metals to form chains of single atoms by gently pulling apart a metallic contact, and to measure the electron transport under different bias conditions. In atomic-sized conductors the traversing electrons may interact with the vibrational degrees of freedom of the atoms in the junction. This inelastic effect was observed by Agraiit $e t$ al. [2] for atomic Au wires as a slight drop in conductance beyond a threshold voltage corresponding to one vibrational mode of the chain.

A full description of the transport properties of atomic-size conductors therefore requires a quantum mechanical treatment of both the electronic and mechanical degrees of freedom. In order to approach the modeling of real devices we here study a one-dimensional tight-binding model of the conducting electrons combined with a balls-and-springs model for the mechanical motion of the nuclei comprising the wire [3]. With the latter we determine the vibrational modes and frequencies for the wires, cf. Fig. 1. The electronic Hamiltonian is expanded to lowest order in these normal modes:

$$
\begin{aligned}
\mathscr{H}^{0} & =\mathscr{H}_{\mathrm{e}}^{0}+\mathscr{H}_{i-\mathrm{ph}}^{\prime}+\mathscr{H}_{\mathrm{con},}^{\prime}, \\
\mathscr{H}_{\mathrm{e}}^{0} & =\sum_{i} \xi_{i} c_{i}^{\dagger} c_{j}+\frac{1}{2} \sum_{i, j} t_{i, j}^{0}\left(c_{i}^{\dagger} c_{j}+\text { h.c. }\right) . \\
\mathscr{H}_{\mathrm{e}-\mathrm{ph}} & =\frac{1}{2} \sum_{\lambda, i, j}\left(\mathbf{M}^{\lambda}\right)_{i j}\left(c_{i}^{\dagger} c_{j}+\text { h.c. }\right)\left(b_{\lambda}^{\dagger}+b_{\lambda}\right) \\
\mathscr{H}_{\mathrm{on}} & =\sum_{\lambda} \Omega_{\lambda}\left(b_{\lambda}^{\dagger} b_{\lambda}+\frac{1}{2}\right) .
\end{aligned}
$$

The non-linear differential conductance vs. bias voltage is calculated using non-equilibrium Green's functions within the self-consistent Born approximation (SCBA). We find that (i) inelastic scattering is due mainly to a single phonon mode and that (ii) softening the effective spring constant between nearest neighbors leads to lower mode energies as well as larger conductance drops, cf. Fig. 2. These conclusions agree well with experiment. Further, (iii) our calculations on chains with different number of atoms suggest that the conductance drop scales linearly with length (up to at least 40 atoms in the wire), cf. Fig. 3. Beyond the threshold voltage electrons start to dissipate energy into the phonon system. Our method takes this into account by considering the energy flow in addition to the mean current, and (iv) reproduces the finite slope in the conductance also observed in experiment caused by this effect, cf. Fig. 2.

\section{References:}

[1] N. Agraï, A. L. Yeyati, and J. M. van Ruitenbeek, Phys. Rep. 377, 81 (2003).

[2] N. Agraït, C. Untiedt, G. Rubio-Bollinger, and S. Vieira, Phys. Rev. Lett. 88, 216803 (2002).

[3] T. Frederiksen, Master's thesis, MIC, Technical University of Denmark (2004).

A full journal publication of this work will be published in the Journal of Computational Electronics. 


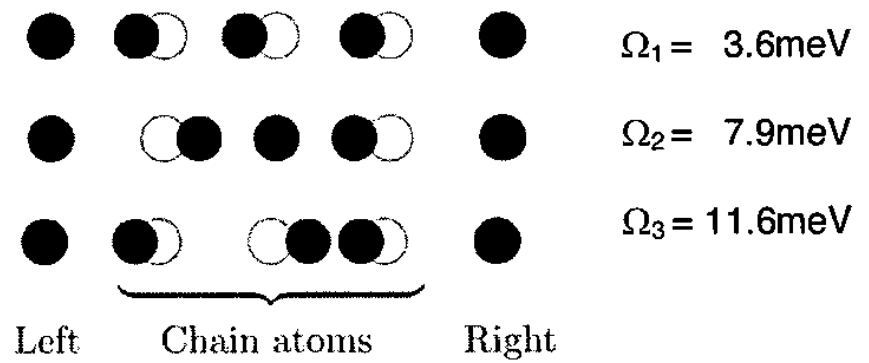

Fig.1: Example of the three vibrational modes of a 3-site chain sandwiched between two electrodes (represented by two end sites).

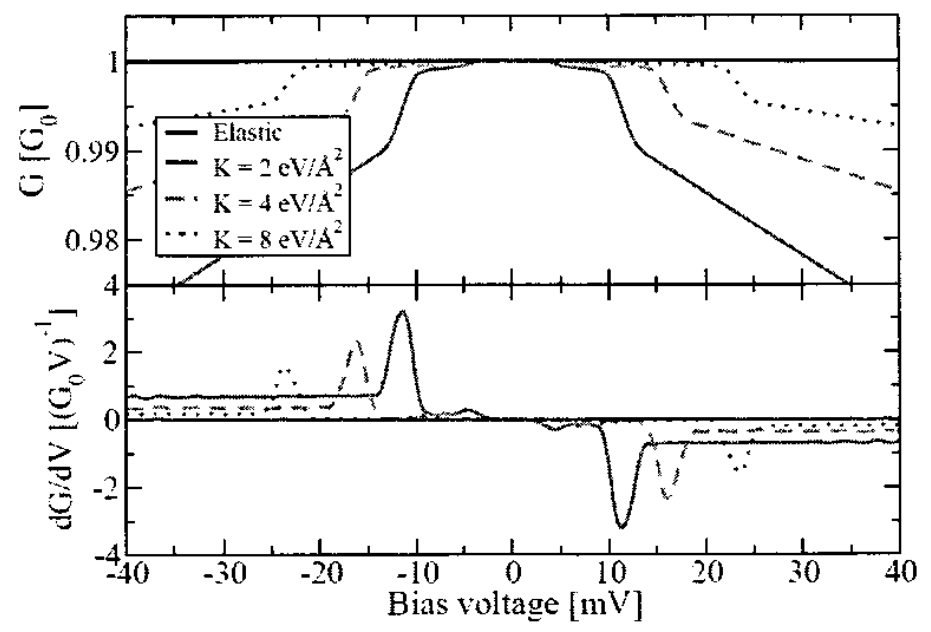

Fig. 2: Calculation of the differential conductance for a 3-site chain. Each line corresponds to a particular value for the effective spring constant between nearest neighbors. The slopes beyond the threshold voltage correspond to energy dissipation in the wire.

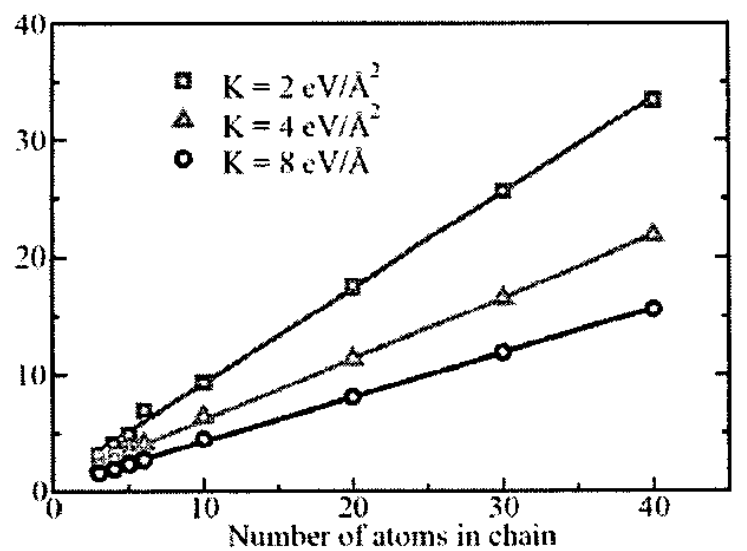

Fig. 3: Conductance drop vs. number of atoms in the chain. One sees that the drop scales linearly with the length of the wire (at least up to around 40 atoms).

A full journal publication of this work will be published in the Journal of Computational Electronics. 